\title{
Transformação da vida de um menino tuyuka no internato salesiano de Pari-Cachoeira: leitura antropológica do internato como uma estrutura total \\ (1970-1979)
}

\author{
Life transformation of a tuyuka boy in the salesian \\ boarding school of Pari-Cachoeira: anthropologic view of \\ the boarding school as a total institution (1970-1979)
}

Duhpo: Justino Sarmento Rezende - Tuyuka ${ }^{1}$

DOI: http://dx.doi.org/10.20435/tellus.v18i37.520

\begin{abstract}
Resumo: O objetivo do artigo é descrever a vida de um menino tuyuka dentro do processo de educação no internato salesiano de Pari-Cachoeira² ${ }^{2}$, no município de São Gabriel da Cachoeira, AM, no período de 1970-1979. A educação de crianças, adolescentes e jovens indígenas dentro de uma estrutura total transforma-os em indígenas com outros ideais diferentes de seus povos. Os estudos de Erving Goffman sobre estrutura total, os estudos de escritores indigenistas e indígenas sobre a dinâmica de internatos na região do alto rio Negro fundamentam o trabalho.
\end{abstract}

Palavras-chave: educação indígena; educação escolar; processo civilizatório.

\begin{abstract}
The purpose of this article is to describe the life of a tuyuka boy in the educational process of the salesian boarding scholl of Pari-Cachoeira in the municipality of São Gabriel da Cachoeira, AM, in the years 1970 till 1979. The education of indigenous kids, teenagers, and yougsters inside of a total institution lead them to have diferent ideals from their own people. The theoretical framework is based on Erving Goffman's concept of total institution, as well as on the studies about the dynamics of the boarding schools in the so called "alto rio Negro" area by indigenist writers and indigenous people.
\end{abstract}

Keywords: indigenous education; school education; civilizing process.

\footnotetext{
${ }^{1}$ Núcleo de Estudos da Amazônia Indígena (NEAI/UFAM), São Gabriel da Cachoeira, Amazonas, Brasil.

${ }^{2}$ O internato nessa missão terminou no ano de 1987. Os salesianos deixaram a missão no final do ano de 1998.
} 


\section{INTRODUÇÃO}

A experiência de vida de um menino tuyuka também representa experiências de outras crianças, adolescentes e jovens indígenas que viveram no mesmo contexto histórico. Os estudos do sociólogo, antropólogo e escritor canadense Erving Goffman sobre as estruturas totais, as pesquisas de indigenistas e pesquisadores indígenas sobre a vida de internatos salesianos do rio Negro fundamentam esse artigo. A missão salesiana em Pari-Cachoeira existiu no período de 1940-1998.

O artigo mostra os processos educativos escolares que marcam profundamente a vida de crianças, adolescentes e jovens indígenas numa perspectiva de educação escolar que visava transformar em "brancos" e "civilizados". Os resultados daqueles momentos são ressignificados e agenciados pelos próprios indígenas em diferentes espaços educativos noutra perspectiva de construção e manejo de uma educação escolar indígena.

\section{HISTÓRIA DOS SALESIANOS}

A história dos salesianos começou na Itália com Padre João Bosco ou conhecido popularmente como Dom Bosco. Ele fundou a Congregação Salesiana (1842) visando contribuir com a educação da juventude da Itália no período da revolução industrial, especialmente, em Valdocco, Turim (Itália). Ali desenvolveu as atividades educativas e profissionalizantes, sustentadas pelos princípios da razão, religião e carinho. Os primeiros estudantes tornaram-se colaboradores e também se tornaram salesianos. A filosofia educacional de Dom Bosco quis "formar bons cristãos e honestos cidadãos" os jovens que frequentaram nas escolas salesianas até aos dias atuais.

No Brasil, os salesianos chegaram em 1883, na cidade de Rio de Janeiro. Em 1894, chegaram a Cuiabá. Em 1915, chegaram a São Gabriel da Cachoeira, Amazonas, com os primeiros salesianos Pe. Bálzola, salesiano Coadjutor José Canudo e Pe. José Scolari. A partir desse período, foram fundadas várias missões: Taracuá, lauareté, Pari-Cachoeira, Barcelos, Tapuruquara, Içana, Cucui, Maturacá e Marauiá. Também, nessa região, os salesianos quiseram formar os indígenas em "bons cristãos e honestos cidadãos". Para atingir tal meta, realizavam as atividades de evangelização, catequese, diversas atividades religiosas (bons cristãos) e 
implantaram a escola e cursos profissionalizantes para se tornarem em "honestos cidadãos". Segundo Costa (2009, p. 25-6) o padre Bálzola dizia:

Nós não recuaremos diante de dificuldades, uma vez que possamos conquistar à fé e à civilização aqueles nossos irmãos de modo a transformar com os nossos suores - que de boa vontade derramaremos - em um ameno jardim, rico das mais formosas flores de Religião e de civilização.

Os empreendimentos causaram sérios impactos. Pode-se dizer como atitudes de desrespeito, desconhecimento e desvalorização das tradições e culturas da região. Nimuendajú dizia que, "das quatro calamidades que pesam sobre os índios: colombianos, negociantes brasileiros, delegados egoístas e missionários intolerantes, estes últimos sejam ainda mais facilmente suportáveis" (CABALZAR; RICARDO, 1998, p. 93). Essas novas formas de educação marcaram profundamente na vida dos estudantes e os pais indígenas. Houve a transformação gradual de valores e práticas culturais, diminuição da utilização das línguas próprias, combate aos cantos e danças rituais, cerimoniais e atuação dos agenciadores especializados: Kumu (Pensadores, agenciadores das forças preventivas e curativas das doenças), Bayaroá (Mestres de Cantos e Danças rituais) e Yaiwa (que realizam a xamanização). Lasmar (2009, p. 23), tratando do ofício do Kumu, diz:

Consiste em fazer uso das potências criativas contidas no conjunto de conhecimentos esotéricos de seu sib para garantir o bem-estar da comunidade de parentes, cuidando para que o equilíbrio dos corpos e do cosmos seja mantido. [...]. Para tanto, ele também deve mediar o contato periódico entre a comunidade e o mundo ancestral, fonte primordial de poder e vitalidade.

\section{INTERNATOS DAS MISSÕES SALESIANAS NO RIO NEGRO}

Eu utilizo a minha própria experiência no internato de Pari-Cachoeira (19701979), município de São Gabriel da Cachoeira ${ }^{3}$, para narrativas sobre a dinâmica da vida no internato. Antes da chegada dos salesianos, nossos avós não possuíam experiências de viverem em internatos, como um lugar de concentração de muitas pessoas da mesma idade ou de várias idades. Os nossos avós nos contavam que

\footnotetext{
${ }^{3}$ Está situado na fisiográfica do Alto rio Negro, no extremo norte do Brasil em uma região conhecida como "Cabeça do Cachorro". Ocupa uma extensão territorial de 112.255km2, com 0,41 habitantes por Km2, o que representa 7,11 da superfície do Estado do Amazonas.
} 
viviam, sim, na Casa dos Saberes ${ }^{4}$, como membros de uma família nuclear. Nessa Casa estavam irmãos maiores e menores, irmãos com serviços de especializados (Kumu, Bayâ, Yaiwa) e irmãos para outros serviços (pescadores, caçadores, preparadores de materiais de rituais).

A minha experiência de aluno interno é compartilhada por diversas pessoas que viveram naqueles períodos, não por aquelas geração pós 1987 que não pegaram mais os internatos. Quando eu tinha nove anos, em 1970, meu pai colocou-me para estudar na missão salesiana e só lá que se estudava, ainda não existiam escolinhas nas aldeias. Foi um dia que eu senti grande diferença entre estar na aldeia e chegar ali no internato, eu não pude falar a minha língua tuyuka, pois meus parentes tuyuka impediam-me dizendo que ali eu poderia falar somente a língua tukano. Tenório (2012, p. 134) diz:

A escola da missão adotou como regra:- Só pode falar língua tukano aqui dentro do colégio! - no caso do tuyuka e das outras línguas, que não o tukano, o que acontece? Como a gente era o minoritário, e todos os jovens naquele tempo eram estudantes, eles entravam na escola com as mães tukano incentivando eles a falar tukano.

No internato, começava uma profunda transformação de minha vida. Sentime mal, inseguro, medroso e vergonhoso. Despertou em mim a vontade de voltar para aldeia, viver com os meus pais e falar a minha língua. Ao mesmo tempo, isso era impossível, eu era apenas uma criança, não podia nem pensar nisso. Se eu conseguisse voltar para casa, os meus pais me trariam de volta. Se os meus pais não me colocassem no internato, eles sofreriam privações de acesso aos bens de civilizados oferecidos pela missão salesiana. Lasmar (2009, p. 20) destaca uma das metas na ação dos salesianos:

Sabemos que o sucesso do empreendimento dos salesianos no alto rio Negro dependia, em larga medida, de eles serem capazes de produzir transformações estruturais no modo de viver da população indígena. [...]. Diziam-se possuidores de um conhecimento a ser transmitido, mas a possibilidade de revelação era de certa forma condicionada à adoção de um novo estilo de vida por parte dos alunos. Em outras palavras, para adquirir este conhecimento era preciso 'civilizar-se'.

\footnotetext{
${ }^{4}$ O termo Casa dos Saberes foi a substituição do termo Maloca, por muito tempo utilizado na nossa região. A Federação das Organizações Indígenas do Rio Negro (FOIRN) que decidiu a troca em sua utilização.
} 
A partir do ano 1973, surgiu outra intervenção no internato, que foi a obrigatoriedade de falar somente a língua portuguesa. Quando falávamos as línguas tukano, tuyuka, desano e outras línguas, os nossos próprios colegas denunciavam junto aos salesianos e aos "assistentes" que eram os próprios indígenas escolhidos pelos salesianos. O resultado disso era ficar de castigo, sendo privado dum desses momentos: almoço, jantar, o mingau; e fazer outras atividades: rachar a lenha e carregar para cozinha etc. Sobre os castigos Goffman (1974, p. 51) afirma:

Os castigos são definidos como consequências de desobediência às regras. Um conjunto de tais castigos é formado pela recusa temporária ou permanente de privilégios ou pela eliminação do direito de tentar consegui-los. De modo geral, os castigos enfrentados nas instituições totais são mais severos do que qualquer coisa já encontrada pelo internado em sua vida fora da instituição. [...]. Os castigos e privilégios são modos de organização peculiares às instituições totais.

Esse controle nos obrigava a aprender e a falar a língua portuguesa, era a demonstração de nosso avanço no caminho do "progresso e civilização". Quem obtivesse certo domínio da língua portuguesa já era considerado e se considerava como "branco" e "civilizado". Do contrário, era considerado "índio" e "atrasado". Tenório (2012, p. 137) assim conta:

Isso era muito forte. Só a língua nacionalmente falada construía pensamentos filosóficos, técnicos, tecnológicos. Essa era língua verdadeira. A língua tukano nunca tinha construído esses pensamentos, técnicas, tecnologias. Era miudinha, não tinha dimensão ampla para poder ser uma língua de universidade, de conhecimento. Era um pinguinho que não valia nada. Esse pensamento era muito forte.

\section{PROCESSO DE EDUCAÇÃO DE CRIANÇAS, ADOLESCENTES E JOVENS INDÍGENAS NO INTERNATO}

Com o tempo nós acostumávamos com o estilo de vida de internato. Estávamos convencidos de que ali era o lugar de estudos e aprendizagem de conhecimentos ligados à vida dos "brancos". Aqui não nos ensinavam os conhecimentos indígenas. Sonhávamos com o mundo do "branco" e dos "civilizados". Nossos professores eram os salesianos e as salesianas. Os indígenas surgiram pouco a pouco, eram os ex-alunos (as) de internatos que os missionários escolhiam 
entre os melhores estudantes. Eles não falavam a língua indígena, só português. Naquela época, não entendia o "por quê" disso. A releitura daquela história, hoje, leva-me a compreender que o indígena professor tinha que ser daquele jeito, ele tinha se formado para ser assim, isto é, igual ao 'branco'.

Os missionários nos ensinavam as técnicas agrícolas, criação de gado, suínos, galinhas; curso de mecânica, marcenaria e alfaiataria. Sampaio (2012, p. 55) observa:

O número de marceneiros, alfaiates, aumentou. Você tinha profissionais, então muita gente começou a se mudar. Quase $85 \%$ dos jovens que aprenderam essas profissões se mudaram para Venezuela e outros para Colômbia. A maioria do alto rio Negro mesmo foi para a Colômbia. Eles arranjaram emprego em obra, fizeram a vida por lá. Mais tarde encontraram mulheres que eles gostaram e se casaram por lá; até hoje, dificilmente eles lembram dos pais.

Os tempos de aulas e os estudos pessoais estavam bem organizados; não faltavam horas de esporte; aprendíamos práticas de vida cristã: missa diária, retiro mensal e catequese.

Enquanto estávamos no internato nossos pais viviam nas aldeias. Na leitura de Goffman (1974, p. 11) pode-se dizer que o internato é uma instituição total. Estávamos vivendo longe de nossas famílias durante meses. Éramos educados num mundo diferente de nossas aldeias. A cada ano, chegava um número aproximado de duzentos alunos. As estruturas estavam bem organizadas: um dormitório para menores e médios; um dormitório para os maiores; dois refeitórios; dois lugares para estudos; três campos de futebol (menores, médios e maiores); e muitos espaços para jogos e diversos jogos para que todos ficassem ocupados; na igreja organizavam: menores e médios; noutra fileira os maiores. Sampaio (2012, p. 51) diz:

Havia três divisões de classe. Maiores, que estavam com 15 anos para frente; médios eram entre 12 e 13 anos; e os mais novos. O dormitório era grande. Era só rede. Então ficava encostado um no outro. Por exemplo, no dormitório couberam 120 alunos, médios e maiores. No dos pequenos couberam mais 90 e poucos. Tinha os assistentes. Um para maiores, outro para médios e outro para menores. Geralmente eram os salesianos. Muitas vezes, eram alunos que já tinham deixado a escola. 
Como forma de resistência e proteção entre nós, formávamos grupos mesclados de alunos maiores e menores. Os alunos maiores tornavam-se protetores dos menores. Essas realidades não nos faziam bem, pois surgiam muitas disputas e brigas. Segundo Goffman (1974, p. 58) trata de panelinhas:

E evidentemente, encontramos unidades ainda menores: "panelinhas", ligações sexuais mais ou menos estáveis; e, o que é talvez mais importante, "formação de pares", através da qual dois internados passam a ser reconhecidos pelos outros como "amigos" ou "casais", e ficam mutuamente dependentes para grande amplitude de assistência e apoio emocional. [...]. Em algumas instituições totais, a equipe dirigente pensa que a solidariedade entre conjuntos de internados pode dar uma base para atividade combinada proibida pelas regras e por isso pode conscientemente tentar impedir a formação de grupo primário.

Os alunos mais fortes eram temidos pelos demais. Segundo Goffman (1974, p. 16), uma das características das estruturas totais é facilitar o cuidado das pessoas incapazes de cuidar de si mesmas. Nós indígenas éramos vistos assim. Em nossas aldeias, nós crianças, adolescentes e jovens sabíamos pescar, fazer roça, caçar e trabalhar segundo a nossa compreensão de mundo. Essas nossas capacidades eram desconhecidas no internato. Não tínhamos nossa liberdade para viver bem nossas vidas. No internato éramos controlados, e nós mesmos controlávamos aos demais, adequando-nos ao estilo de vida de uma estrutura total.

Os nossos pais poucas vezes nos visitavam devido às distâncias geográficas. Depois que nos deixavam no internato, eles somente vinham participar das programações religiosas: Páscoa (março/abril), festa de Nossa Senhora Auxiliadora (maio) e Festa de Dom Bosco (agosto). Quando vinham para essas festas, traziam alimentos típicos de nossa cultura. Fora desse calendário religioso, de vez em quando alguma pessoa da aldeia aparecia, trazia alguns alimentos enviados por nossos pais.

Nas festas religiosas, chegavam todos os moradores das aldeias. Os missionários, para envolvê-los, organizavam várias celebrações, procissões, torneios para disputas entre os moradores de diversas regiões. Nós internatos também tínhamos nossas equipes de trabalho e de esporte. Além das atividades religiosas, de esportes, eram distribuídas as refeições para os festeiros. Para Goffman (1974, p. 87) a festa é uma das características das estruturas totais: 
As pessoas da administração e os internados "se misturam" através de formas padronizadas de sociabilidade - por exemplo, comem juntos, participam de jogos de salão, ou de bailes. Nesses momentos, os internados e os dirigentes têm licença para "tomar liberdades", apesar das fronteiras de casta. [...] Há distribuição de presentes e pequenas indulgências aos internados; alguns deveres de trabalhos são cancelados.

Apesar de eu ter dito que, com o tempo, nós acostumávamos ao internato, não deixávamos de sentir a dureza dos tempos de trabalho, das disciplinas rigorosas e dos castigos. Para o extravasamento das tensões e os pesos que sentíamos era importante a prática de esporte, torneios, cinema aos domingos, apresentações mensais de teatros e passeios mensais. As estruturas totais, segundo Goffman (1974, p. 18), "realizam atividades diárias de forma grande e com horários rigorosamente disciplinados". O símbolo de controle da disciplina do internato era o badalo do sino (sinos nos dormitórios, no refeitório, no estudo; sino da igreja); no trabalho, no esporte e banho era apito do salesiano ou "assistente" indígena.

Para cada ano, adquiríamos experiências novas. Na medida em que passávamos de ano ganhávamos mais segurança e dominávamos os menores. O perfil do salesiano marcava positiva e negativamente a nossa vida. Quando o salesiano era compreensível, amigo e animador nós caminhávamos bem. Com o salesiano incompreensível e disciplinador, castigador sentíamos muito mal, sofríamos, ficávamos medrosos e inseguros. Goffman (1974, p. 19) através de seus estudos mostrou que:

A equipe dirigente muitas vezes vê os internados como amargos, reservados e não merecedores de confiança; os internados muitas vezes veem os dirigentes como condescendentes, arbitrários e mesquinhos. Os participantes da equipe dirigente tendem a sentirem-se superiores e corretos; os internados tendem, pelo menos, sob alguns aspectos, a sentirem-se inferiores, fracos, censuráveis e culpados.

Através dos processos da evangelização, catequese, escolarização e a profissionalização de internos, os salesianos provocaram mudanças culturais. A parte religiosa exercia influências fortes na nossa formação humana, na nossa personalidade. Um clima misturado de medo e alegria, frente às ideias da morte e vida eterna, de pecado e graça, inferno e céu fortalecia a disciplina (obediência) de internato e a 'docilidade' dos jovens. Segundo Goffman (1974, p. 95): 
As cerimônias e os divertimentos dos domingos são às vezes considerados como opostos; nas instituições totais, isso pode ser entendido, em parte, como duplicação desnecessária de função. Como as atividades esportivas e as representações de caridade, cerimônia religiosa é um período em que a unidade entre a equipe dirigente e os internados pode ser demonstrada por indicar que, em alguns papeis não-significativos, todos participam da mesma audiência, diante do mesmo ator estranho.

Os seus métodos educativos suscitavam em nós os "choques", "estranhamentos", "medos", "tramas", "traumas". Essas realidades posteriormente foram muito narradas às gerações posteriores aos internatos. Por outra parte, os mesmos processos criavam em nós o "apego" e o "gosto" por tais métodos. Sobre isso (2009, p. 47-8), eu destaco:

É possível perceber diversas marcas da educação salesiana que hoje influenciam a ação do indígena professor na escola e dificultam a discussão sobre a educação escolar indígena. A marca da contradição. Os indígenas professores se consideram vítimas da história da escola salesiana, porém na prática assumem as mesmas atitudes dos salesianos da época. [...]. Uma característica muito presente na prática de indígenas professores é a compreensão da escola como um progresso e um processo civilizador. [...]. É aversão e revolta em relação ao tema da escola indígena, por entender que ela significa o atraso, a volta ao passado indígena. Assim, há adoção de conteúdos escolares desligados da realidade indígena, por se entender que a escola deve ensinar aquilo que os indígenas não sabem, isto é, conteúdos das realidades não indígenas.

Em meio à complexidade de fatores da vida de internato, ficava claro para nós que estávamos ali para estudar e estudar. O internato significava lugar de estudo, da aprendizagem dos conhecimentos do 'branco', criar sonhos com o mundo dos 'civilizados' e sonhar em conquistar coisas novas. A vida era dirigida de forma bem organizada, com os horários detalhados, avaliações mensais medidas pelas notas de comportamentos. Assim mediam a nossa aprendizagem e a construção da pessoa, que se propunham formar: "honesto cidadão e bom cristão". Lasmar (2009, p. 26) escreve:

[...] a estrutura curricular dos internatos facultava aos alunos a aprendizagem de ofícios manuais como costura e carpintaria, capacitando-os a produzir objetos 'de branco', além de lhes garantir acesso aos conhecimentos que, segundo asseguravam os missionários, permitiriam que os índios se 
tornassem, eles próprios, padres ou 'doutores'. À medida que se ampliou a influência salesiana, cresceu a importância da formação escolar completa. A maioria das famílias passou a não medir esforços para ver um filho completar os estudos e conseguir um trabalho assalariado. É significativo que, entre as atividades mais prestigiadas, destaquem-se as de professor e auxiliar de enfermagem, profissões que se relacionam, respectivamente, com a transmissão do saber escolar e com a cura das doenças.

A permanência no internato era de oito meses, e quatro meses com a família. O curto tempo de permanência com a família não era suficiente para aprender os ensinamentos de nossos avós. Apesar desse tempo curto, o meu avô transmitia-me alguns conhecimentos. Mas sabia que eu não Ihe daria o resultado esperado.

Por outra parte, havia a proibição para a realização das cerimônias e rituais de cada povo. O cristianismo "controlava" a vida das pessoas. Os mestres de nossos saberes e suas práticas eram considerados como agenciadores dos poderes do "diabo" e eram vistos como o "atraso". Em algumas aldeias praticavam-se às escondidas. Andrello (2014, p. 178), diz:

O acesso a sal, sabão, roupas, terçados, machados, anzóis, espingardas e munição, obtidos até então por meio do endividamento com os patrões da seringa e do caucho, passava a ser negociado nas missões a partir das primeiras décadas do século XX, em que os termos do escambo eram estritamente determinados pelos padres. Entregar conjuntos de adornos cerimoniais, derrubar as grandes malocas, abandonar os rituais e o xamanismo foram as exigências impostas.

Eu estudei em Pari-Cachoeira [1970-1979] como aluno interno até concluir a 8a série. O sistema educativo empreendido ensinou-nos muitas coisas novas. Não se ensinavam os valores indígenas. Assim gerava progressiva separação ao nosso modo de educação. Com os primeiros alunos internos, o sistema educacional não abalou a base da educação dos povos indígenas, pois eles já possuíam base firme cultural e permaneciam pouco tempo no internato. A partir do final da década de 1960 que entravam adolescentes e jovens. Para os missionários ficava bem evidente de que quanto mais cedo entrássemos no internato, com mais facilidade tornaríamos 'civilizados' e nossos pais acreditavam nisso, também. Segundo Goffman (1974, p. 60-1): 
Uma terceira tática padronizada no mundo da instituição é a "colonização": o pouco do mundo externo que é dado pelo estabelecimento é considerado pelo internado como o todo, e uma existência estável, relativamente satisfatória, é construída como o máximo de satisfações possíveis na instituição. A experiência do mundo externo é usada como ponto de referência para demonstrar como a vida no interior da instituição é desejável, e a usual tensão entre os dois mundos se reduz de maneira notável; também se reduz nitidamente o esquema de motivação baseada nessa discrepância percebida, e que descrevi como peculiar às instituições totais. [...]. Um quarto modo de adaptação ao ambiente da instituição total é o da "conversão": o internado parece aceitar a interpretação oficial (ou da equipe dirigente) e tenta representar o papel do internado perfeito.

O deslocamento físico-cultural, da aldeia para internato, impediu o processo educativo indígena [Tuyuka, Tukano, Desano, Piratapuia, Wanano, Tariano etc.]. Barreto (2013, p. 20) conta:

[...] estava com meu avô Ponciano Barreto, especialista, Yai, conhecido como Ponciano Yai, considerado o último grande especialista tukano da região do Rio Tiquié. Respeitado pelo seu ofício e procurado por todos da região. Até os meus cinco anos de idade estive sob seus cuidados, como seu neto preferido para assumir o seu ofício quando falecesse. [...]. Todavia não pude cumprir o seu projeto como seu sucessor por ser conduzido a seguir à proposta de educação dos missionários. Meu rumo de vida se voltou para o estudo convencional, com objetivo de superar aquela condição que tanto minha mãe reclamava. Tendo terminado o ensino primário, isto é, até a quarta série, fui continuar meus estudos no colégio salesiano, em regime de internato, que fica num distrito de Pari-Cachoeira... [...]. Foi quando perdi o contato definitivamente com meu avô, e, consequentemente, estava comprometida minha formação de Yai.

No momento em que nós poderíamos passar pelos rituais de iniciação, estávamos sendo iniciados em outros ritos ocidentais para começarmos ser não índios, isto é, civilizados. Fomos habilitados e qualificados para participarmos dessas cerimônias. Goffman (1974, p. 23) diz:

Se a estada do internado é muito longa, pode ocorrer, caso ele volte para o mundo exterior, o que já foi dominado "desculturamento" - isto é, "destreinamento" - que o torna temporariamente incapaz de enfrentar alguns aspectos da vida diária. 
Ano após ano, nos distanciávamos dos rituais e cerimônias de nossos avós. E, muitos nem fomos iniciados conforme nossas tradições. Essa realidade preocupava os mais velhos, nossos avós. Muitas vezes, eu ouvi o meu avô falando com outros velhos: "os nossos valores, cantos, danças, rituais, cerimônias, um dia vão acabar, pois nossos netos se tornarão como 'brancos'”. João Rivelino Barreto (2012, p. 26) conta:

O sistema educativo implantado pelos salesianos trouxe benefícios e também perplexidades, sobretudo, pela reação violenta aos conhecimentos indígenas associados às práticas rituais de "benzimento" que foram proibidas e hostilizadas, passando a ser entendida como coisas anormais e diabólicas por missionários que atuaram em seu tempo e realidade.

Na década de 1970, havia a negação da identidade indígena e aversão às culturas nossas. Nós não estávamos educados para amar as nossas tradições indígenas. A nossa meta era a chegar como os "não índios", "civilizado": falando a língua portuguesa, costumes, profissão. Os nossos pais quando um filho já sabia falar a língua portuguesa diziam: o meu filho já é 'branco'! Esta situação gerava orgulho aos jovens, pais, professores, salesianos e ao governo. Barreto (2013, p. 20).

Minha mãe sempre me motivou a estudar, tomando a vida dos missionários como exemplo de vida tranquila e abastada, como prêmio de longos anos de estudos bem sucedidos. Ela almejava isso a todos os seus filhos, na certeza de salvaguardar a dura vida de roçado e de penúria.

No final da década de 1970, surgiram as preocupações conosco e com as nossas culturas. Surgiram críticas ao modelo escolar vigente, prática salesiana de educar e evangelizar. Andrello (2014, p. 178), afirma que "a partir dos anos 1970, adotando paulatinamente outra prática pastoral, para o que a denúncia de etnocídio de que foram alvo em 1980 no Tribunal Bertrand Russell, Roterdã, haveria de contribuir".

Falava-se que as escolas tinham que valorizar as culturas indígenas nas escolas. A nova interpretação daquela história gerou conflitos entre os indígenas e missionários. Os indígenas acostumados com as práticas da 'civilização' entendiam a proposta de valorização das culturas indígenas como a volta ao seu passado [ser indígena]. Alguns salesianos insistiam para que nós recuperássemos nossas 
práticas culturais, mas tinham outros que não queriam. Estava começando uma nova compreensão histórica da escola, compreensão dos povos indígenas. Andrello (2014, p. 178) mostra as mudanças:

Apareceram então padres que pretenderam pôr fim a certas comemorações cívicas antes impostas aos índios, eliminar as missas que se faziam por ocasião das formaturas nos internatos e, mais significativamente, promover "festas culturais", para os quais os ex-alunos indígenas eram agora instados a retomar cantos e danças a fim de apresentá-los no próprio ambiente da missão. O resultado imediato foi uma nova perplexidade: "a gente não chega a entender a civilização", ponderam os moradores de hoje nos centros missionários, pois quem poderia imaginar que tudo que fora antes condenado passaria a ser vivamente recomendado?

Em Pari-Cachoeira nas reuniões de pais, algumas lideranças tradicionais diziam que a finalidade da escola deveria ser ensinar os conhecimentos das sociedades 'civilizadas' para seus filhos e filhas. Diziam que os filhos e filhas não estavam na escola para aprender as culturas indígenas.

Somente na década de 1980, após a aprovação da Nova Constituição Federal do Brasil e com os compromissos das Associações e Organizações Indígenas, assessoria [antropólogos, linguistas...] das entidades não indígenas que começou o trabalho de conscientização pela valorização das culturas indígenas. Esta nova mentalidade surge dentro de um delicado processo de negociação entre aquilo que os jovens, lideranças, pais e comunidades sonham como fortalecimento das culturas e identidades indígenas. Domingos Barreto (2012, p. 59-60) conta:

Ao longo dos anos 2000, a Foirn começa a analisar essas experiências piloto e outros projetos de escola criados no período, como lições que estavam dando certo. Avalia que já possuímos experiências aprendidas em uma política municipal, estadual ou federal. Discutimos em nossas reuniões que não iríamos chegar a fazer isso de qualquer forma, mas conduzindo e ampliando essa experiência nas políticas públicas no nível regional, partindo dos resultados e das lições das escolas piloto. Para isso precisávamos que existisse uma incorporação dessas experiências como política pública, não poderia ser separado; e as comunidades tinham que estar preparadas, entendendo o que estava acontecendo. 


\section{CONSIDERAÇÕES FINAIS}

As releituras antropológicas das trajetórias de minha vida e dos outros adolescentes e jovens mostram que passamos por profundas transformações humanas. Cada um de nós chegou até onde chegou, também por aquela educação recebida dos salesianos. Essas transformações foram percebidas pelos nossos pais, por nós mesmos, pelos salesianos e pela sociedade brasileira pela demonstração de qualidades de nossa educação.

Os pesquisadores não indígenas e indígenas sobre as realidades dos internatos obtiveram grandes resultados em suas produções acadêmicas: trabalhos de conclusão, dissertação de mestrados e teses de doutorados. Após trinta e sete anos de os internatos terem fechados, os seus ex-alunos continuam ocupando vários espaços sociais, na política partidária, nas escolas como professores, coordenadores, pedagogos e gestores; outros estão assumindo as secretarias de educação a nível municipal; outros ocupam cargos de assessorias no estado e a nível nacional; os primeiros protagonistas da implementação da educação escolar indígena no rio Negro foram os ex-alunos dos internatos. Assumiram o protagonismo nesse novo desafio de construir as escolas indígenas, pois haviam se apropriado das mazelas de outro modelo escolar ocidental. Eles não queriam que as novas escolas fossem semelhantes aos modelos de internatos. Não conseguiram mudar totalmente, pois eles mesmos haviam passado do modelo ocidental para iniciar o outro modelo. O modelo antigo ainda serviu como referencial para se repensar uma nova educação escolar indígena.

Os estudos da Antropologia Social ajudam-me a entender as diversas situações que eu vivi e diversas atividades introduzidas em nossa região por não indígenas e aquilo que nós mesmos indígenas fomos aceitando e pedindo. Os meus cinquenta e sete anos são importantes, pois me fazem entender de maneira nova aquilo que eu mesmo escrevi, pensei e senti na minha própria pele. Diante de muitas coisas que os não indígenas escreveram sobre nós e nossas histórias, podemos reescrever. Os nossos estudos acadêmicos nos oferecem instrumentos para olhar nossas culturas, nossos conhecimentos e nossas vidas como resultados de diversas transformações.

O artigo mostra como nós fomos transformados pela estrutura total - internato, como todos os agentes internos e externos estavam interligados com os 
interesses externos de nossos pais e do governo do Brasil: sermos "civilizados"; "ser bons cristãos e honestos cidadãos".

\section{REFERÊNCIAS}

ANDRELLO, Geraldo. Cultura ou parentesco? Reflexões sobre a história recente do alto rio Negro.R@U,Revista@ntropológica da UFSCAR, São Carlos, SP, v. 6, n. 1, p. 175-89, jan./jun. 2014.

BARRETO, Domingos. A FOIRN na história das políticas de educação. In: CABALZAR, Flora Dias (Org.). Educação Escolar Indígena do Rio Negro (1998-2011): relatos de experiência e lições aprendidas. São Paulo: Instituto Socioambiental; São Gabriel da Cachoeira, AM: Federação das Organizações Indígenas do Rio Negro - FOIRN, 2012. p. 58-61.

BARRETO, João Paulo Lima. Wai-Mahsa: peixes e humanos. Um ensaio de Antropologia Indígena. 2013. Dissertação (Mestrado em Antropologia Social) - PPGAS, UNIVERSIDADE FEDERAL DO AMAZONAS (UFAM), Manaus, AM, 2013.

BARRETO, João Rivelino Rezende. Formação e transformação de coletivos indígenas no noroeste amazônico: do mito à sociologia das comunidades. 2012. Dissertação (Mestrado em Antropologia Social) - PPGAS, Universidade Federal do Amazonas (UFAM), Manaus, AM, 2012.

CABALZAR, Aloisio; RICARDO, Carlos Alberto. Povos indígenas do alto e médio rio Negro: uma introdução à diversidade cultural e ambiental do noroeste da Amazônia brasileira. São Paulo: Instituto Socioambiental; São Gabriel da Cachoeira, AM: FOIRN - Federação das Organizações Indígenas do Rio Negro, 1998.

COSTA, Mauro Gomes da (Org.). A ação dos salesianos de Dom Bosco na Amazônia. São Paulo: Editora Salesiana, 2009.

GOFFMAN, Erving. Manicômios, prisões e conventos. São Paulo: Perspectiva, 1974.

LASMAR, Cristiane. Conhecer para transformar: os índios do rio Uaupés (Alto Rio Negro) e a educação escolar. Revista Tellus, Campo Grande, MS, ano 9, n. 16, p. 11-33, jan./jun. 2009.

REZENDE, Justino S. Da escola com os salesianos para a escola indígena. In: COSTA, Mauro Gomes da (Org.). A ação dos salesianos de Dom Bosco na Amazônia. São Paulo: Editora Salesiana, 2009.

SAMPAIO, Álvaro. Tempo de viver separado. In: CABALZAR, Flora Dias (Org.). Educação Escolar Indígena do Rio Negro: relatos de experiência e lições aprendidas. São Paulo: Instituto Socioambiental; São Gabriel da Cachoeira, AM: Federação das Organizações 
Indígenas do Rio Negro - FOIRN, 2012. p. 50-7.

TENÓRIO, Higino. Impactos das políticas linguísticas tuyuka. In: CABALZAR, Flora Dias (Org.). Educação Escolar Indígena do Rio Negro: relatos de experiência e lições aprendidas. São Paulo: Instituto Socioambiental; São Gabriel da Cachoeira, AM: Federação das Organizações Indígenas do Rio Negro - FOIRN, 2012. p. 134-45.

\section{Sobre o autor:}

Justino Sarmento Rezende - Tuyuka: É indígena do povo 甘htãpinoponaTuyuka, nascido na aldeia Onça-Igarapé, distrito de Pari-Cachoeira, município de São Gabriel da Cachoeira, Amazonas. É padre salesiano. Doutorando em Antropologia Social (PPGAS/UFAM), membro do Núcleo de Estudos da Amazônia Indígena (NEAI/UFAM) e bolsista do FAPEAM. Mestre em Educação (UCDB/ MS). Bacharel em Teologia (FTNSA/SP) e Graduado em Filosofia (UCB/DF). E-mail: justinosdb@yahoo.com.br

Recebido em 29 de maio de 2018 Aprovado para publicação em 24 de agosto de 2018 